\title{
Private Valuation Parameters of Efficiency the Investment Projects in the Concept "Compramultifactor"
}

\author{
Aidar Puryaev ${ }^{1}$ \\ ${ }^{1}$ Department of Production Management, Kazan (Volga region) Federal University, Naberezhnye Chelny, \\ Russian Federation \\ Correspondence: Aidar Puryaev, Department of Production Management, Kazan (Volga region) Federal \\ University, Russian Federation. Tel: 8-917-268-8319. E-mail: aidarp@mail.ru
}

Received: May 18, 2015

Accepted: June 29, 2015

Online Published: September 30, 2015

doi:10.5539/mas.v9n11p263

URL: http://dx.doi.org/10.5539/mas.v9n11p263

\begin{abstract}
The new concept of evaluating the effectiveness of investment projects is offered. A dynamic multi-factor complex of private parameters of investment projects' evaluation in engineering and their classification is developed. The recommendations of global and locally-oriented destination are worked out. The foundation for the application of fuzzy set theory in the evaluation of investment projects has been laid.
\end{abstract}

Keywords: desirability function, efficiency evaluation compromise, fuzzy sets, linguistic variables, private valuation parameters

\section{Introduction}

This article is devoted to the development of private valuation parameters (PVP) on the effectiveness of engineering, customer recommendations (investors, decision-makers) and the supervisory authorities at the level of state and the region on the proposed seven PVP groups and on the proposed by the author concept of evaluating the effectiveness of "Compramultifactor" (see. Figure 1). The concept "Compramultifactor" the meaning of the investment project's (IP) efficiency refers to the following. The effectiveness of IP is a category, reflecting a compromise compliance with the limits of investment project and (or) the desired level by private evaluation parameters $(P V P)$ of different physical nature of a dynamic multi-factor complex parameters. In this case it refers to the efficiency of the whole project.

All of the taken above PVP are found on the basis of the analysis of factors' influence on the process of evaluating the effectiveness, the best project's selection and on the basis of conclusion strictly in accordance with the proposed principles of developed concept. The concept "Compramultifactor" and how it works is being presented in (Puryaev, 2011).

There is also offered the opportunity in sharing all the private valuation parameters into seven groups on appropriate grounds into two categories: specific and non-specific.

Under the non-specific investment project's PVP in this paper it refers to the parameter having common properties, which are independent of the specific conditions of investment activity (IA) or the specifics of the investment project (IP). Specific PVP IP - is a parameter characterizing the conditions of specific investment projects and depending on the specifics of this IP. Specific parameters for the evaluation of the described (as examples) in this work projects of melting and molding casting areas of operations (MCO) upgrading in foundry engineering is taken on the basis of the analysis of the "iron casting's production" in general; technological subsystems of melting and molding casting operations associated with iron in particular; existing methods of selection of technological processes' appropriate option of iron's melting and casting (Puryaev, Rybkina \& Zakirova, 2014b; Puryaev, Rybkina \& Zakirova, 2014a). 




Figure 1. The concept's scheme of efficiency estimation of IP "Compramultifactor"

On formal grounds all that PVP IP can be quantitative or qualitative. Qualitative PVP may be represented in the form of linguistic variables (LV) to its set-term or in the form of expert evaluations (points).

On the basis of the orientation all PVP can be locally-oriented and globally-oriented. Locally-oriented PVP these are the parameters that by the content carry local and private interest from the perspective of the primary business unit's investment activities. According to the parameters constraints (desired levels) are set directly by the customer (investor or decision-makers). Globally-oriented parameters reflect on their content global, common interest with the position of the state, region and other non-primary participants of investment activity. Restrictions (desired levels) according to the parameters established by the relevant supervisory (control) authorities at the level of state and region. Under the supervisory authority of state and region meant federal agencies, services and department of the state's executive authorities of the Russian Federation and their authorized representatives in the regions. They develop a restrictions' scale on globally-oriented private valuation parameters.

As supervisory authorities on globally-oriented PVP the following government agencies are recommend:

1. Federal Service for Supervision in the Sphere of Natural Resource Use Department of the Interior of the Russian Federation: resource security parameter.

2. Federal Science and Innovation Agency, Federal Education and Science Supervision Agency of Ministry of 
Education and Science of the Russian Federation: the parameter of scientific and technical security.

3. Service for Ecological, Technological and Atomic Supervision of the Russian Federation Government: parameter of ecological and social responsibility; indicator of environmental impact assessment of external and internal environment.

4. Federal Service for Financial and Budget Supervision of the Ministry of Finance of the Russian Federation: parameter of macroeconomic significance.

5. Federal Service for the Supervision of Public Health and Social Development: social group settings (injuries, occupational diseases).

\section{Results}

The following PVP of IP effectiveness in mechanical engineering are offered.

2.1 A Group of Public-Meaningful Private Parameters of Estimation and Optimization (Globally-Oriented, Non-Specific).

2.1.1 Parameter of Resource Security (Security of the Region, the Country in Terms of Delivery Depends on Strategic Resources from the Side)

A special case of it may be setting of energy resource security (in terms of energy supply). This state-significant parameter is recommended to determine as an indicator of the share of own strategic resources in terms of value (in prices at the beginning of the project) of the total volume of strategic resources used in IP $\left(R S=\frac{C_{O S R}}{C_{\sum S R}} \times 100, \%\right)$.To strategic resources in the work recommended to include: production of oil-refining, gas processing and chemical industries; production of ferrous metals, nonferrous metals and other public-significant resources. It is recommended to the supervisor to set the scale limits on this parameter as a function of a fuzzy set and a strict list of strategic resources. That is setting RS must be submitted as a linguistic variable (LV RS) "share of their own strategic resources of the total volume employed in the IP strategic resources". The following term-set for LV RS is recommended (Shtovba, 2015): T(RS) = \{inadmissible, satisfactory (average share), good (high share) excellent (very high share)\}. The supervisor, using the received semantic rule $\mathrm{M}$, for each value (of term) of a given set must establish its meaning, i.e., set limits and (or) desirable levels for the underlying variable RS (indicators with numeric values) in the form of fuzzy numbers. For example, (see. Figure 2):

$\mathrm{M}($ (“unacceptable“ $)=\{(0 ; 1.0),(20 ; 1.0),(30 ; 0.5),(40 ; 0.0)\}$

$\mathrm{M}$ (“satisfactory”) $=\{(20 ; 0.0),(30 ; 0.5),(40 ; 1.0),(50 ; 0.5),(60 ; 0.0)\}$

$\mathrm{M}($ "'good" $)=\{(40 ; 0.0),(50 ; 0.5),(60 ; 1.0),(70 ; 0.5),(80 ; 0.0)\}$

$\mathrm{M}($ ("excellent" $)=\{(60 ; 0.0),(70 ; 0.5),(80 ; 1.0),(100 ; 1.0)\}$.

It is assumed that the higher the score is, the lower is the dependence of the project on the delivery of strategic resources from side i.e., higher is the level of resource security of the country (region). The first number in brackets - is the underlying variable of RS - the share of own strategic resources in terms of value (in prices at the beginning of the project) of the total strategic resources used in IP $\left(R S=\frac{C_{O S R}}{C_{\sum S R}} \times 100, \%\right)$, and the second number - this corresponds to a particular value of the membership function of RS (takes a value between 0 and $1)$. 


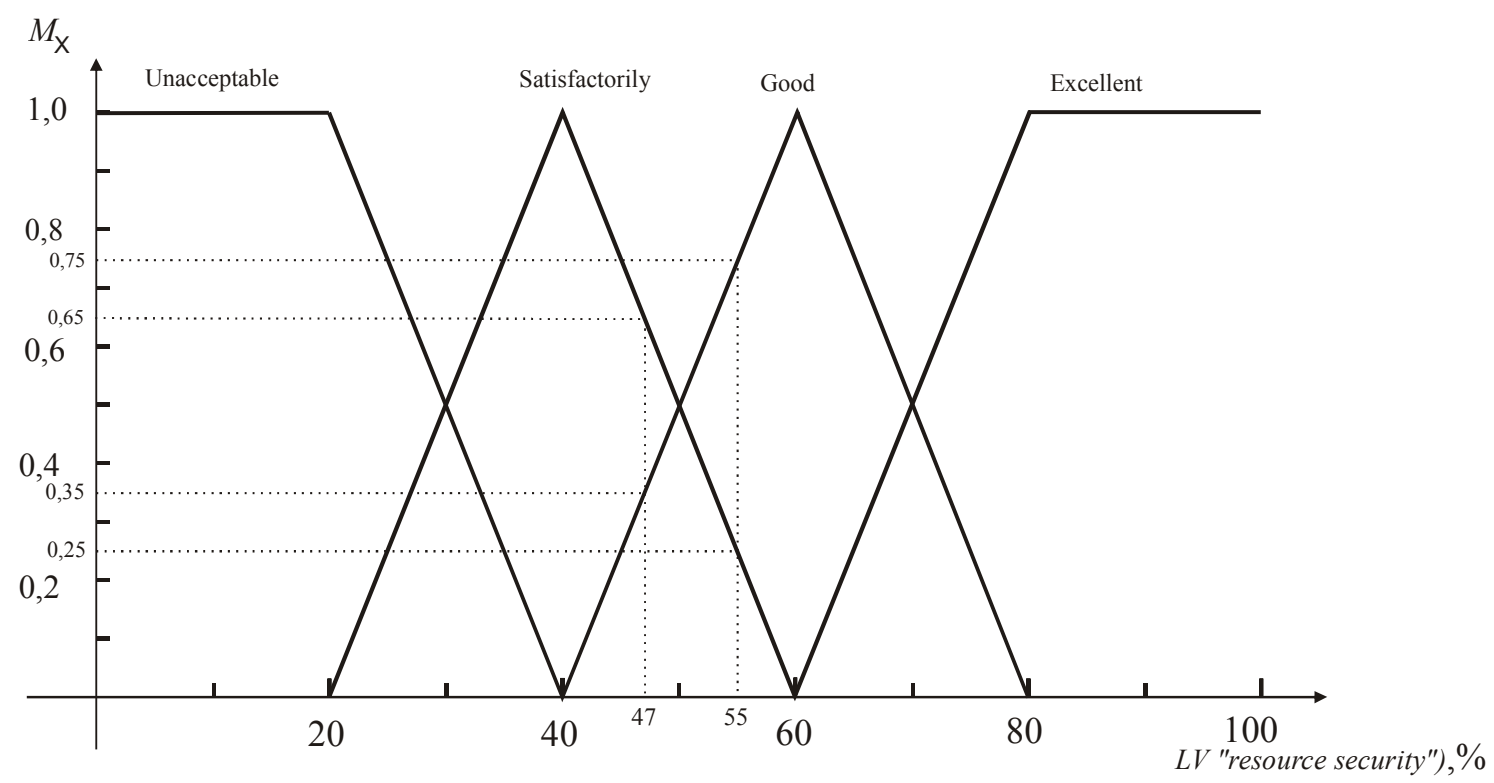

Figure 2 - The functions belonging terms of linguistic variables resource security (LV "resource security")

This means that each estimated parameter of the given IP (LV RS) will have two evaluations using the fuzzy set shown in Figure 2. For example, for the value of $\mathrm{RS}=55 \%$ will correspond to the following two estimates: "good" $\left(\mu_{55}=0.75\right)$ and "satisfactory" $\left(\mu_{55}=0.25\right)$. Or for meaning RS $=47 \%$ : "satisfactory" $\left(\mu_{46}=0.65\right)$; "good" $\left(\mu_{46}=0.35\right)$. Thus, characterized by illegibility, uncertainty of evaluated information that corresponds to a real situation of choice.

2.1.2 Parameter of Scientific and Technical Security (Security of the Country, the Region in Terms of the Application of Scientific and Technological Innovations in the Project)

This state-significant parameter is offered to express through the index of the import-substituting innovations' share $\left(Q_{I S I}\right)$ in the IP of the total number of innovations in the IP $\left(Q_{I}\right)-\mathrm{STS}, \%$. That is if the indicator is presented in the form of a clear set, then it is defined as $S T S=\frac{Q_{I S I}}{Q_{I}} \times 100, \%$. In that case, if the indicator is presented in the form of a linguistic variable (LV STS) "share of import-substituting innovation in total innovation of IP", then we recommend that for him the following term-set: T(STS) $=\{$ inadmissible, satisfactory (average share), good (high share) excellent (very high share)\}. Each term LV STS should be presented in the form of a fuzzy number, similar to the example from section 1.1 of this group of PVP. Values of fuzzy numbers are quantitative values of STS, calculated with the way, mentioned above. The absence of the term "unacceptable", or rather its replacement by term "bad" is presented on the desired level of PVP STS, but not as severe restriction. That is, in the absence of import substitution innovations in all the alternative projects (and only in all!) investment projects are deviated. In this case it is recommended to evaluate alternative IP LV "number of innovations" - NN. Supervisory authorities are recommended to submit a rating scale as a term-set $\mathrm{T}(\mathrm{NN})=\{$ unacceptable, satisfactory, good, excellent $\}$ with a strict restriction.

2.1.3 Parameter of Ecological and Social Responsibility (ESR) - Parameter of IP's Responsibility Towards Society and the World

Today it is difficult to separate the corporate social responsibility (at the level of a country, region) and the world as a whole. Society is a component part of the world (ecology). Public health is the main benefit and value for which it's necessary to make an effort, to spend time. Causing detritment, damage to the environment, causes damage to society itself: exacerbate existing diseases, new diseases appear. Social responsibility is recommended to be classified into the following types: a) responsibility to society as a whole (by country, region). Viewed from the perspective of the state level and can be considered as a state-significant parameter; b) responsibility to consumers of products (quality, warranty, post-warranty service, etc.). Viewed from the perspective of local 
participants of IP: primary business entities, shareholders and investors. Object of orientation: consumers of products; c) responsibility to the staff and members of IP. It is already considered within the enterprise, on IP which is implemented. Object of orientation: the staff, participants of IP. Thus, it becomes clear that the last two types of implied social responsibility are inadequate (unrepresentative) from a position of national importance. More significantly (even much!) for state indicators are emissions of harmful substances (carbon dioxide, methane and other greenhouse gas) into the atmosphere. According to them strict restrictions are set in the Kyoto Protocol (Kyoto Protocol to the United Nations Convention on Climate Change; Piskulova, 2006; Kokorin, 2005) for all signatory countries (including Russia). Kyoto Protocol (an international instrument adopted in Kyoto (Japan) in December 1997, in addition to the United Nations Framework Convention on Climate Change FCCC) has become a global agreement on the protection of the environment. The main aim of this document is to reduce from the period of 01 January 2008 through 31 December 2012, the total anthropogenic gas emisions (6 types) in the equivalent of carbon dioxide, causing greenhouse effect, by 5.2\% compared to levels of 1990 . Russia signed the Kyoto Protocol in March 1999, ratified on October 22, 2004 (Piskulova, 2006) on the condition not to exceed the level of greenhouse gas emissions recorded in 1990 (limitation of emissions: 100\% of the 1990 level). Federal law came into force in February 16, 2005. One of the market mechanisms of flexibility that have been developed at the 7th Conference of the Parties FCCC, held in late 2001 in Marrakech (Morocco) and approved at the 1st Meeting of the Parties of the Kyoto Protocol (Montreal, Canada) from 28 November to 9 December 2005 is emission trading according to which state or individual economic entities in their territory may buy or sell quotas for greenhouse gas emissions at the national, regional or international markets. Recommended by us to potential of ecological and social constraints of object ID is the value engineering quotas for greenhouse gases in carbon dioxide equivalent. Scale assessment in this case (in the case of a strict definition of the information available) may be given in the form of clear scale numbers. Russia, a signatory to the Kyoto Protocol, sooner or later, will still have to develop a national registry of greenhouse gas emissions, to create a national stock exchange on Trading Scheme for greenhouse gases. For the case where no national registry of greenhouse gases is developed, we recommend parameter of in the form of LV ESP "greenhouse gases in carbon dioxide equivalents" to the term set T(ESP) $=\{$ unacceptable, satisfactory, good, excellent $\}$. Or as a quality indicator of expertise "greenhouse gases in carbon dioxide equivalents", similarly estimated by expert assessment of environmental impact assessment index (see below p. 2 of this complex PVP or LV ESP for each of these values (terms) should be presented in the form of fuzzy numbers with values of emissions. The emissions shall be determined on the basis of the implementation of the Kyoto Protocol's quantified limitation and reduction of emissions per unit of real potential GDP (for example, 1 million rubles), and taking into account the units to create added value (AV) considered by the investment project.

2.1.4 Parameter of Macroeconomic Significance (Parameter of Significance for the Country in Terms of Increasing the Gross Domestic Product (GDP))

This state-significant parameter can be expressed through linguistic variable (LV R $\Delta \mathrm{AV}$ ) "average annual growth rate of real potential value added (at constant prices of the base year)". For the base year should take a year of bringing GDP, adopted in Russia's national accounts or the year of beginning of the project in the absence of accepted base. For LV R $\triangle \mathrm{AV}$ recommended term-set is $\mathrm{T}(\mathrm{R} \Delta \mathrm{AV})=\{$ inadmissible, satisfactory, good, excellent $\}$. Each value of a term-set is necessary in this case be represented as fuzzy set. As the values of fuzzy number is recommended average annual growth rate of real value added $\mathrm{R} \Delta \mathrm{AV}$, calculated as follows. Shall consider the case of IP implementation on existing mechanical production, which is necessary to evaluate. Here it is necessary to use the difference method for estimation $A V$ In this case, it must be firstly calculated the real value added data without the project $\left(A V_{t I}\right)$ over the expected life cycle of the project $(T)$. Then determine the same, but with version "with the project" $\left(A V_{t 2}\right)$ Further, according to the formula (1) to determine the increase in $A V\left(\Delta A V_{t}\right)$ by years of implementation:

$$
\begin{aligned}
& \Delta A V_{t}=A V_{t 2}-A V_{t 1}=\left(M V P_{t 2}-C R I_{t 2}-C C_{t 2}-C O P_{t 2}-G I O_{t 2}\right)- \\
& \left(M V P_{t 1}-C R I_{t 1}-C C_{t 1}-C O P_{t 1}-G I O_{t 1}\right), p y \sigma
\end{aligned}
$$

$M V P_{t 1}, M V P_{t 2}$ - market value of the product of the project in the "no project" and "with the project", respectively, rubs.

$C R I_{t 1}, C R I_{t 2}$ - costs of raw materials, items in versions "without project" and "with the project", respectively, rub.

$C C_{t 1}, C C_{t 2}$ - costs of components in versions "without project" and "with the project", respectively, rub. $C O P_{t 1}, C O P_{t 2}-$ costs of outsourcing options in "without project" and "with the project", respectively, rub 
$G I O_{t 1}, G I O_{t 2}$ - grown investment options to periods "without project" and "with the project", respectively, rub.

For convenience of comparison the resulting figure with GDP growth at the regional level, countries (macroeconomics) is necessary to transfer it in relative units (\%\%) - the growth rate of $A V$ by the formulas (2), (3):

$$
\begin{array}{r}
R \Delta A V_{t}=\frac{\Delta A V_{t}}{A V_{t 1}} \times 100, \% \\
R \Delta A V=\frac{\sum_{t=0}^{T} R \Delta A V_{t}}{T}
\end{array}
$$

$R \triangle A V_{t}$ - the growth rate of the real potential value added by the life-cycle of a project $(\mathrm{T})$.

$R \triangle A V$ - average annual growth rate of real potential added value of the project.

The obtained value of $R \Delta A V$ project should be compared with the scale of the restrictions that the supervisor should represent as function of fuzzy set with a certain preset-term, for example, $T(\triangle A V)=\{$ unacceptable, satisfactory, good, excellent $\}$. To do this, the supervisor, using the received semantic rule $\mathrm{M}$, for each value (term) of a given set must establish its meaning, i.e., set limits and (or) desirable levels for the underlying variable $R \triangle A V$ (indicators with numeric values) in the form of fuzzy sets (for example, as in Figure 2).

In the case when a project is created on the "open field", i.e., created a new company (enterprise), then from the perspective of indicators calculated by the formula (2), it is the best, the most important, because in the denominator is necessary to set 0 и $R \Delta A V_{t} \rightarrow \infty$. But for comparing similar projects, this indicator does not work. For such projects (comparability is one of the principles of developed concept) a new evaluation index is needed. There are two alternative measures recommended in using:

- absolute growth rate of real potential for the $A V$ project's life cycle $-\triangle A V$, thousand of rub. The higher the value of this index, the more it is significant from the standpoint of the economy as a whole. Supervisory authorities should introduce on the scale restrictions of this parameter as a function of fuzzy set with a certain pre-set term, for example, $T(\triangle A V)=\{$ unacceptable, satisfactory, good, excellent $\}$.

- a relative measure of efficiency - efficiency of resource using (Genkin \& Kozlova, 2004) - ERU. The average value of this indicator over the life cycle of implemented IP is suggested to calculate according to the formula:

$$
E R U=\frac{\sum_{t=0}^{T} A V_{t}}{\sum_{t=0}^{T} C R_{t}} \times 100, \%
$$

$\sum_{t=0}^{T} C R_{t}$ - the average cost of resources for the project's life cycle, rub. To estimate the macroeconomic significance it is sufficient to apply a static approach (without discounting procedure) If we apply the $L V$ "productive use of resources", the procedure for establishing the scale limitations of this variable similarly the procedure of establishing, for example in the parameter $L V R S$.

\subsection{Ecological Group (Globally-Oriented and Locally-Based, Non-Specific and Specific)}

2.2.1 Environmental Impact Assessment Index EAI of Outdoor Environment (Territory of the Enterprise; Residential Neighborhood)

This globally-oriented specific parameter is purely qualitative and is recommended to be evaluated (as the name implies) by expert. I.e. to assess this type of parameters it's necessary to attract independent environmental experts (at least 3) and to carry out an objective assessment of the weighted average from the outside. As the scale of assessment can recommend "fourpoint" system with five gradations (see. Table 1). Restriction or desired level for a given parameter is set centrally relevant by supervisory authority in the form of ranking point.

2.2.2 Environmental Impact Assessment Index EAI of Indoor Environment (Environment of the of IP Implementation: Enterprise, Workshop, Defined territory)

The assessment of this globally-focused non-specific parameter is released absolutely similarly as the evaluation 
of the previous parameter.

Environmental group of parameters includes the following locally-oriented, specific factors of the working environment of production area for IP in upgrading of foundry production: dust, harmful substances, noise, vibration and intensity of thermal radiation, i.e., those that are common to most used in foundries in the technological processes that account for the largest number of complaints. Under the by harmful substances implied content of harmful gases with different toxicological properties, characterized by four classes of danger (in descending order). For quantitative assessment and comparison of environmental parameters of various technological processes as their values in physical units $\left(\mathrm{kg} / \mathrm{t}, \mathrm{W} / \mathrm{m}^{2}\right.$, and others.), can be used, and the relative dimensionless quantities proposed by researchers, authors of the article (Kukuj \& Lazarenkov, 1992). Researchers for taking into account all the above considered factors of production environment was proposed comprehensive assessment of working conditions in the form of pollution index $\left(C_{p}\right)$, representing the sum of the values of the factors of production relations sphere to their allowable values. They are the values of $C_{p}$ for the various technologies and equipment foundry.

2.2.3 For the Project Of Modernization of the Steel Melting Shop of Land and Land of MMO We Have Determined as a Result of Research and Proposed to Use the Following Locally-Oriented Specific Quantitative PVP, Limitations and (or) Desirable Levels Which are Set Directly by Decision-Maker

- Thermal radiation, $\mathrm{W} / \mathrm{m}^{2}$.

- Noise, dB.

- Vibration, dB.

- Dust, $\mathrm{kg} /$ tons.

- Harmful substances, $\mathrm{mm}^{3} /$ tons.

\subsection{Social Group (Globally-Oriented, Non-Specific)}

\subsubsection{Injuries}

The proportion of the production area occupied by automated equipment and technological process of the total production area $\left(A P A=\frac{S_{A P A}}{S_{\Sigma}} \times 100, \%\right)$. This parameter is a quantitative and allows to give tight restrictions. But it's recommended to apply the scale restrictions on this parameter as a function of the scale of fuzzy sets, i.e., This parameter is represent as LV APA - "share of automated production area of the total volume production area" with the next term set $\mathrm{T}(\mathrm{APA})=\{$ inadmissible, satisfactory (average share), good (high share) excellent (very high percentage) $\}$. The supervisor authority using the adopted semantic rule $\mathrm{M}$ for each value (term) of a given set must establish its meaning, i.e., set limits and (or) desirable levels for the underlying variable APA $A P A=\frac{S_{A P A}}{S_{\Sigma}} \times 100, \%-$ indicators with numeric values) in the form of fuzzy sets, like LV RS, presented in item 1.1 of given complex of PVP.

\subsubsection{Complex Index of Injury}

For assessment the social group in these qualitative parameters it is recommended to include the following indicators which will be evaluated and weighed by the expert: the procedure of worker's certification for compliance with profession; potential (or used) format safety regulations (labeling, progressive work wear and protective equipment); potential (or current) micro-social environment in the enterprise. Methods of assessing of the complex refractive discussed further in identifying of the group of quality parameters. Restriction or desired level for a given parameter set centrally by relevant supervisory authority in the form of ranking point.

\subsubsection{Occupational Diseases}

The coefficient of labor protection by technological process. This indicator can be represented as a parameter quantitative evaluation of the level of occupational and technological processes' safety $\left(Q^{T}\right)$, which is calculated by the method proposed by researchers (Tkachenko \& Doktorovich, 1990):

$$
Q^{T}=C^{T} \times C^{E}
$$

$C^{T}$ - coefficient of labor protection, depending on the technological operations: 


$$
C^{T}=\frac{\sum O^{S}}{\sum O}
$$

$\sum O^{S}$ - sum of all safe and harmless procedures in this process;

$\sum O-$ total number of all operations of this process.

$C^{E}$ - coefficient of the labor protection of employees:

$$
C^{E}=\frac{\sum E^{S}}{\sum E}
$$

$\sum E^{S}$ - number of all employees in the safe and harmless operations;

$\sum E$ - number of employees in all operations of the process.

$Q^{T}$ can range from 0 to 1 and must be the passport characteristics, calculated by technologist-developer. The name of coefficient $Q^{T}$, above mentioned does not accurately reflect its essence. Therefore, we have another to way of its name correction. Coefficient $Q^{T}$ legitimate will be called as quantitative evaluation of the level of occupational safety of technological process of workers. So, this indicator in its essence is also related to the injury, i.e., located at the junction of two parameters: injuries and occupational diseases. From our position it is important to take it into account when assessing, but not as attributed to one or the other parameters.

\subsubsection{Complex Index of Occupational Diseases}

In this qualitative parameter in assessing of social group it is recommended to include the following indicators to be assessed and weighed by expert: the potential (or used) format of workers' preventive health care (presence of a dispensary, the presence of special devices and rooms for relaxation, trips to resorts and dispensary, the number of health workers); balanced diet.

\subsection{Technical and Technological Group (Locally-Oriented, Specific IP)}

For technical and technological groups of private parameters' estimates for IP of melting blocks' upgrading, consisting in the evaluation and selection processes of melting iron aggregate existing alternatives is recommended include the following parameters:

1. The type and brand of cast iron (possibility of melting particular brand of iron).

2. The maximum processing temperature of the melt, ${ }^{\circ} \mathrm{C}$.

3. Minimum content of sulfur after melting, $\times 10^{-2} \%$.

4. Group (category) of the complexity of casting on the grounds 1,3,5,6-10.

5. The cycle of melting and holding, hours.

6. Maximum Performance, tons / hour.

7. Type of production (compliance to type).

For the project of upgrading the area of molding casting areas of operations (MMO), consisting in the evaluation and selection processes of iron casting together existing alternatives is recommended to include the following parameters:

1. The type and brand of cast iron (possibility of filling a particular brand of cast iron).

2. Grade of accuracy by one-piece size.

3. Grade of accuracy by split size.

4. Roughness grade of castings.

5. Group (category) of the complexity of casting on the grounds 1,3,5,6-10.

6. The thickness of the main walls, $\mathrm{mm}$.

7. Weight of produced castings, $\mathrm{kg}$.

8. Coefficient of metal yield ( $\left.\mathrm{m}_{\text {casting }} / \mathrm{m}_{\text {liquid metal }}\right)$.

9. Coefficient of metal utilization ( $\mathrm{m}_{\text {detail }} / \mathrm{m}_{\text {casting }}$ ). 
10. Type of production (compliance to type).

11. Maximum Performance, tons / hour.

12. Duration of the casting process, hour.

Values shown in parameters mentioned above are strictly defined (some -passport characteristics of technological processes), so there is no need to set the scale of the restrictions as a function of fuzzy set, it is enough to set limits and (or) desirable levels for them in the form of clear numbers and (or) quantitative intervals and a nominal scale.

\subsection{Resource Group (Locally-Oriented, Specific Parameters)}

This group can be divided into several subgroups. We recommend the following subgroups with specific private parameters estimates for IP modernization of the steel melting site of iron foundry production

\subsubsection{Material and Technical Costs:}

a) cost of the lining of the melting furnace (unit), rub / ton.

b) cost of charge material (burden, fluxes, modifiers), rub / ton;

c) effective period of operation of fixed assets IP, years;

d) returns on assets, rub / rub.

\subsubsection{Power Consumption:}

a) technological costs of electricity, $\mathrm{kW} \times$ hour/tons;

b) expenses of compressed air, $\mathrm{m}^{3} /$ tons;

c) process fuel expenses, tons/tons.

\subsubsection{Labor Costs:}

Unit Man-Hours, Person×Hour / Tons Or Norm-Hour /Tons.

\subsubsection{Financial Expenditure:}

a) specific production cost, rub / ton;

b) average variable expenses, rub / ton;

c) standard of working capital, thousands of rubles.

These parameters characterize the resource-costly side of a specific IP. For all of these parameters are set limitations and (or) the desired levels directly by decision-maker (customers, investors). Limitations of these parameters may be as fuzzy numbers (if there is more convincing verified information, such as processing expenses of energy, fuel and compressed air to produce a ton of liquid metal are passport characteristics), as well as the scale of fuzzy sets (in uncertainties or asymmetrical information available, for example, the specific cost of production, returns on assets, efficient operation period of fixed assets).

\subsection{A group of High-Quality Unclassified Parameters (Locally-Based, Non-Specific Parameters)}

\subsubsection{Complex Index Quality of Functions' Performing (QFP), Points; (Non-Specific)}

Under the quality of performance of the functions $(Q F P)$ it refers to the quality of the object that performs or should perform the function (function group) (Kac \& Kovalev, 1984). It is also proposed by researchers (Kac \& Kovalev, 1984) to use the following method of expert assessment of this indicator. The essence of an object depends on the specific IP. Under the object for the IP upgrading of melting or molding and casting operations considered in this paper, refers to the technological process of melting or casting respectively. Firstly, for each function (or group of functions) of the object (e.g., functions are implemented in each process to modernize existing area) set specifications, e.g.,

a) mechanical, physical-chemical properties (strength, hardness, wearing quality of construction, the accuracy of heat and chemical composition of the alloy);

b) operational and technical economic parameters (speed of function, effectiveness factor, power consumption);

c) reliability indicators (longevity, persistence, reliability);

d) maintainability requirements, standardization and unification of spare parts;

e) ergonomic and aesthetic requirements of the project. 
Under the ethical and ergonomic requirements in the study there meant properties that characterize the appearance of the object and working conditions, created by object. Secondly, for each characteristic coefficient of weighting is determined which is showing the relative importance of this property among others (eg, subjective or based on the method of paired comparisons (Kac \& Kovalev, 1984, p.143-146). Thirdly, experts assess the level of implementation of technical requirements in each variant IP in the form of verbal evaluations "excellent", "good", "satisfactory", etc. Further, these estimates are converted to equivalent units - points using a special scale. Quite enough is fourpoint scale with five gradations achieved with precision of the expert method (see. Table 1).

Table 1. Fourpoint scale with five gradations (Kac \& Kovalev, 1984)

\begin{tabular}{lc}
\hline Verbal evaluation & Numerical score \\
\hline excellent & 4 \\
good & 3 \\
satisfactorily & 2 \\
barely passable (at the limit) & 1 \\
unacceptably & 0 \\
\hline
\end{tabular}

Complex index of $Q F P$ in each case calculated as the sum of the scores, adjusted weighting coefficients' properties (requirements) by the formula:

$$
Q F P=k_{\text {corr }} \sum_{i=1}^{n} B_{i} k_{w i}
$$

$k_{\text {corr }}$ - correction coefficient, inverting $Q F P$ into zero, if only just one point turns out to be 0 . Correction coefficient increases the complex index of $Q F P$ with positive evaluations (good, excellent) and underestimates at rest. It is not allowed to use this factor into account only when there is no zero grade. It's defined by the formula (Kac \& Kovalev, 1984):

$$
k_{\text {corr }}=0,9\left(B_{1} B_{2}, \ldots B_{n}\right)^{0,1 / n}
$$

$B_{i}$ - score with $i$-properties (requirements);

$k_{w i}$ - weighting coefficient of $i$-properties (requirements).

The maximum value of the complex index of $Q F P$ valued on a scale shown in Table 1, is equal to $4, \sum_{i=1}^{n} k_{w i}=1$. For the project "technical process of melting iron" we have established the following rational functions, technical requirements for these functions and their corresponding weighting coefficients (see. Table 2).

Table 2. Evaluation of quality of functions' performing ( $Q F P)$

\begin{tabular}{lcc}
\hline \multicolumn{1}{c}{ Functions (F) } & Technical requirements & Weighting coefficient \\
\hline F1 "Smelting cast iron" & $\begin{array}{c}\text { Melting speed } \\
\text { F2 "Overheating cast iron" }\end{array}$ & 0.15 \\
F3 "Technological excerpt cast iron at & $\begin{array}{c}\text { Reed and accuracy of } \\
\text { overheating } \\
\text { Retentivity t } \text { toverheat }_{\text {overheat" }}\end{array}$ & 0.20 \\
F4 "Formation of predetermined & $\begin{array}{c}\text { Accuracy and consistency of the } \\
\text { chemical composition cast iron" }\end{array}$ & 0.20 \\
F1, F2, F3,F4 & Repairability & 0.25 \\
F1, F2, F3,F4 & Unification of replacement parts & 0.10 \\
TOTAL & & 0.10 \\
\hline
\end{tabular}


It should be noted that the method of expert assessment of quality parameters may be suitable for calculating all the other following parameters of this groups well as for all available quality parameters of developed complex (for example, the complex index of occupational accidents and diseases).

\subsubsection{Complex Index of Uncertainty and Risk Investment of Enterprise, Points (Non-Specific).}

In this high-quality parameter estimation is recommended to take the following parameters to be evaluated and weighed by expert:

1. macroeconomic risks (inflation, the increased cost of production suppliers);

2. uncertainty in with deliveries of strategic resources;

3. uncertainty with the marketing network (dealer network, distribution channels);

4. uncertainty in transaction costs of IP (explicit and implicit, for example, the cost impact of third parties);

5. political risks (the change of government, the president, socio-economic structure);

6. uncertainty in micro social environment;

Let's show on hypothetical example evaluation of this parameter - the complex index of uncertainty and risk IP companies - especially the calculation of all quality parameters (parameters which can not be represented in the form of LV and clear quantitative indicators) of developed complex PVP. Example of calculations is presented in Table 3 below.

Table 3. Expert evaluation parameter "Complex index of uncertainty and risk"

\begin{tabular}{|c|c|c|c|c|c|c|c|}
\hline \multirow[t]{3}{*}{ Indicators of uncertainty and risk (i) } & \multirow{3}{*}{$\begin{array}{c}\text { Weighting } \\
\text { coefficient, } \\
\mathrm{k}_{\mathrm{wi}}\end{array}$} & \multicolumn{6}{|c|}{ Experts (j) } \\
\hline & & & 1 & & 2 & & \\
\hline & & $\mathrm{B}$ & $\mathrm{B}_{\mathrm{E}} \cdot \mathrm{k}$ & B & $\mathrm{B}_{\mathrm{E}} \cdot \mathrm{k}$ & B & $\mathrm{B}_{\mathrm{E}} \cdot \mathrm{k}$ \\
\hline 1. Macroeconomic risks (inflation, the increased & & & & & & & \\
\hline cost of production suppliers) & 0,2 & 3 & 0,6 & 3 & 0,6 & 2 & 0,4 \\
\hline $\begin{array}{l}\text { 2. Uncertainty in with deliveries of strategic } \\
\text { resources }\end{array}$ & 0,2 & 2 & 0,4 & 3 & 0,6 & 2 & 0,4 \\
\hline $\begin{array}{l}\text { 3. Uncertainty of the marketing network } \\
\text { (distribution network, distribution channels) }\end{array}$ & 0,1 & 1 & 0,1 & 2 & 0,2 & 2 & 0,2 \\
\hline $\begin{array}{l}\text { 4. Uncertainty in transaction costs of IP (explicit } \\
\text { and implicit, for example, the cost impact of third } \\
\text { parties) }\end{array}$ & 0,3 & 1 & 0,3 & 2 & 0,6 & 1 & 0,3 \\
\hline $\begin{array}{l}\text { 5. Political risks (a change of government, the } \\
\text { president, socio-economic structure) }\end{array}$ & 0,1 & 4 & 0,4 & 4 & 0,4 & 3 & 0,3 \\
\hline 6. Uncertainty in micro social environment & 0,1 & 3 & 0,3 & 4 & 0,4 & 3 & 0,3 \\
\hline $\mathrm{B}_{\mathrm{Ej}}$ & 1,0 & & 2,1 & & 2,8 & & 1,9 \\
\hline$\frac{\sum_{j=1}^{3} B_{E j}}{3}$ & & & & & 2,27 & & \\
\hline
\end{tabular}

Thus, the complex index of uncertainty and risk, which includes 6 mentioned above parameters, of conditional IP appreciated by expert by 4 scoring scale at 2.27 .

2.6.3 Complex Index of Other Special Requirements of the Customer (Investor, Decision-Maker) of IP.

In this subgroup ungraded quality parameters the specific requirements of a particular IP may be included.

For example, for the IP of smelting iron foundry area modernization we recommend: uninterrupted supply of liquid alloys of $M C O$; equipment $M I S$ (management information system) technological process; production flexibility (various brands of iron smelting, applicability to different types of production). The assessment of this complex parameter evaluation is carried out similarly to evaluation of complex parameter uncertainty and risk. 


\subsection{Economic Group (Locally-Based, Non-Specific PVP).}

In this group of PVP is recommended to take officially accepted parameters of estimation procedure of investment projects (Kossov, Livshic \& Shahnazarova, 2000) and limit investment in IP.

2.7.1 The Internal Rate Of Project Profitability (IRR), \%

2.7.2 Pure Current Value of the Project (NPV), rub.

2.7.3 Investment Payback Period (Discounted), Periods of IP.

\subsubsection{Capital Investments in the Project (KV), Rub.}

Restrictions on these parameters are set locally, i.e. directly by decision-maker in the form of strict limitations and (or) desirability.

\section{Conclusion}

In order to evaluate the effectiveness of the investment project in relation to the object of engineering, applying the concept "Compramultifactor", it is firstly necessary to obtain estimates of PVP meanings all the proposed seven groups by project (projects). In the case where it is impossible to evaluate a particular IP option on any parameter, then that IP should be excluded from the list of possible alternatives, otherwise, the principle of matching and identity by PVP is violated.

When setting the scales in the form of linguistic variables is necessary to generate rules for the functioning of evaluation system (FES). The recommended procedure for the formation, consisting of stages:

1. Split scale restrictions of LV (or set quantitative intervals of admissibility) at the following intervals: unacceptable, satisfactory, good, excellent (for a globally-oriented variables broken down by the supervisory authority).

2. Choose the type of schedule for constructing the function of a fuzzy set (for globally-oriented variables selected by the supervisory authority). The simplest and most used: triangular, trapezoidal, campanulate.

3. Draw the graph, setting the scale of the abscissa (quantity meanings of intervals of each term LV) and the scale of the ordinate (the values of the membership function of these intervals $\mu_{\mathrm{x}}$ ) - for globally-oriented variables constructed by the supervisory authority. It is recommended that terms of proposed and developed above linguistic variables represented as fuzzy sets with triangular membership function (see. Figure 2). In Figure 2, the following terms are represented by triangular membership functions:

$$
\begin{gathered}
\mu_{\text {"unacceptable" }}(u)=\left\{\begin{array}{c}
1, \text { if } u \leq 20 \\
-0,05 u+2, \text { if } u \in(20 ; 40)
\end{array}\right. \\
\mu_{\text {"satisfactory" }}(u)=\left\{\begin{array}{c}
1, \text { if } u=40 \\
0,05 u-1, \text { if } u \in(20 ; 40) \\
-0,05 u+3, \text { if } u \in(40,60)
\end{array}\right. \\
\mu_{\text {"good" }}(u)=\left\{\begin{array}{c}
1, \text { if } u=60 \\
0,05 u-2, \text { if } u \in(40 ; 60) \\
-0,05 u+4, \text { if } u \in(60,80)
\end{array}\right. \\
\mu_{\text {"excellent " }}(u)=\left\{\begin{array}{c}
1, \text { if } u \geq 80 \\
0,05 u-3, \text { if } u \in(60 ; 80)
\end{array}\right.
\end{gathered}
$$

After obtaining estimates of all values parameters for all private alternatives ends in principle, the procedure of forming complex PVP.

Designed and recommended set of private parameters of evaluating the effectiveness of engineering IP seems as a dynamic multi-factor complex. I.e. this complex PVP may, if necessary, change qualitatively and quantitatively depending on the specifics of the estimated investment projects. 


\section{References}

Genkin, B. M., \& Kozlova, M. I. (2004). O pokazateljah jeffektivnosti i principial'nyh shemah motivacii jeffektivnoj raboty [About efficiency indicators and schematic diagrams of effective work motivation]. Vestnik INZhJeKONa. Serija «Jekonomika», 4(5), 3-9.

Kac, G. B., \& Kovalev, A. P. (1984). Tehniko-jekonomicheskij analiz i optimizacija konstrukcij mashin [Technical and economic analysis and optimization of machines]. Moscow: Mashinostroenie, pp: 214.

Kiotskij protokol k ramochnoj konvencii organizacii ob\#edinennyh nacij ob izmenenii klimata. [Kyoto Protocol to the United Nations Convention on Climate Change. Retrieved July 3, 2015, from http://unfccc.int/resource/docs/convkp/kprus.pdf

Kokorin, A. O. (2005). Izmenenie klimata: Obzor sostojanija nauchnyh znanij ob antropogennom izmenenii klimata [Climate Change: A Review of the state of scientific knowledge about man-made climate change]. RRJeC, GOF, WWF Rossii, pp: 20.

Kossov, V. V., Livshic, V. N., \& Shahnazarova, A. G. (2000). Metodicheskie rekomendacii po ocenke jeffektivnosti investicionnyh proektov. Vtoraja redakcija [Methodical recommendations about an assessment of investment projects efficiency: (Second edition)]. (p.421). Moscow: «Economy».

Kukuj, D. M., \& Lazarenkov, A. N. (1992). Kompleksnaja ocenka uslovij truda v litejnom proizvodstve [Comprehensive assessment of the working conditions in foundry production]. Litejnoe proizvodstvo, 11, 30-31.

Piskulova, N. A. (2006). Kiotskij protokol: vozmozhnosti dlja Rossii.: Komplekt uchebnyh materialov po programme kursa" Gosudarstvennoe upravlenie prirodopol'zovaniem" [The Kyoto Protocol: Opportunities for Russia.: training package on the course program "State environmental management"]. Moscow: MGIMO, WWF Rossii, pp: 88.

Puryaev, A. S. (2011). Kompromissnaja ocenka jeffektivnosti investicionnyh proektov. Issledovanie i razrabotka [Compromise assessment of investment projects efficiency. Research and development]. Saarbrucken: LAP LAMBERT Academic Publishing, pp: 276.

Puryaev, A. S., Rybkina, E. A., \& Zakirova, L. G. (2014). The example of an assessment and selection of the optimal variant of technological process of iron smelting. Life Sci J., 11(11), 151-156.

Puryaev, A. S., Rybkina, E. A., \& Zakirova, L. G. (2014). The Method of assessment and selection optimal technological decision (by the example of the choice of cast iron smelting technology). Life Sci J., 11(9), 544-549.

Shtovba, S. D. (2015). Vvedenie v teoriju nechetkih mnozhestv i nechetkuju logiku [Introduction to the theory of fuzzy sets and fuzzy logic]. Retrieved from http:// matlab.exponenta.ru/fuzzylogic/book1/

Tkachenko, S. S., \& Doktorovich, A. S. (1990). Ocenka sostojanija ohrany truda na uchastkah litejnogo ceha [Assessment of the state of labor protection in the areas of the foundry]. Litejnoe proizvodstvo, 8, 29-30.

\section{Copyrights}

Copyright for this article is retained by the author(s), with first publication rights granted to the journal.

This is an open-access article distributed under the terms and conditions of the Creative Commons Attribution license (http://creativecommons.org/licenses/by/3.0/). 